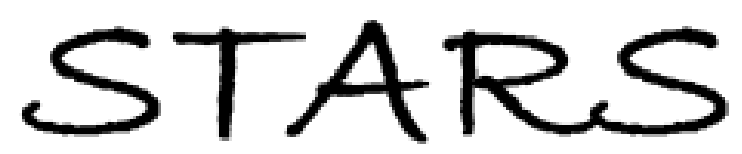

University of Central Florida

STARS

Faculty Scholarship and Creative Works

8-10-2020

\title{
A Practical Guide to Scholarly Activity for Health Sciences Librarians
}

Terri Gotschall

University of Central Florida, terri.gotschall@ucf.edu

Shalu Gillum

University of Central Florida College of Medicine

Nadine Dexter

UCF College of Medicine

Part of the Health Sciences and Medical Librarianship Commons, and the Medical Education Commons

Find similar works at: https://stars.library.ucf.edu/ucfscholar

University of Central Florida Libraries http://library.ucf.edu

This Paper is brought to you for free and open access by STARS. It has been accepted for inclusion in Faculty Scholarship and Creative Works by an authorized administrator of STARS. For more information, please contact STARS@ucf.edu.

\section{Original Citation}

Terri Gotschall, Shalu Gillum \& Nadine Dexter (2020) A Practical Guide to Scholarly Activity for Health Sciences Librarians, Medical Reference Services Quarterly, 39:3, 220-237, DOI: 10.1080/

02763869.2020 .1769422

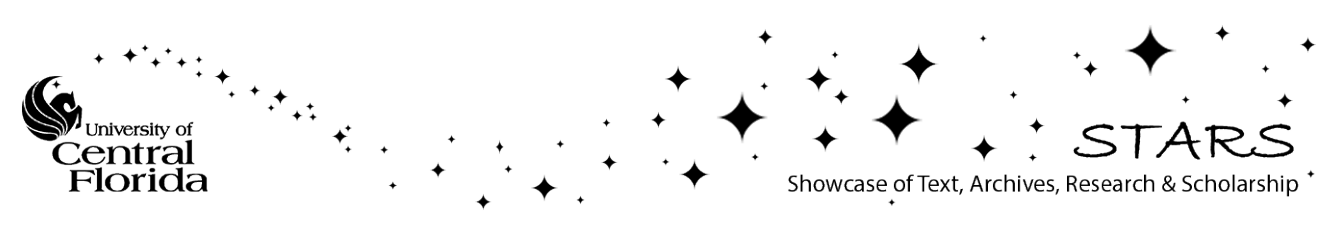




\title{
A Practical Guide to Scholarly Activity for Health Sciences Librarians
}

\author{
Terri Gotschall \\ Shalu Gillum \\ Nadine Dexter
}

\begin{abstract}
This guide to scholarly activities provides early- and mid-career health sciences librarians with a path to immersing in scholarly activities. The four levels walk librarians through increasing stages of scholarship. Early-career librarians will begin at the first level, navigating from discovering mentors and areas of research interest to level two, publishing a resource or book review and finding their first public speaking opportunity. More experienced librarians will find where they are on the path and continue to build their scholarship all the way to conducting and publishing original research and becoming leaders in their field.
\end{abstract}

\section{KEYWORDS}

Scholarly activity, health sciences librarian, medical librarian, publishing

\section{AUTHOR AFFILIATIONS}

Terri Gotschall, MLIS, AHIP (terri.gotschall@ucf.edu) is Scholarly Communications Librarian, Harriet F. Ginsburg Health Sciences Library, University of Central Florida College of Medicine, Orlando, FL, USA (corresponding)

Shalu Gillum, JD, MLS, AHIP (halu@ucf.edu) is Head of Public Services, Harriet F. Ginsburg Health Sciences Library, University of Central Florida College of Medicine, Orlando, FL, USA 
Nadine Dexter, Ed.D, MLS, D-AHIP (nadine.dexter@ucf.edu) is Director of the Health Sciences

Library, Harriet F. Ginsburg Health Sciences Library, Co-Director of Medical Informatics, University of Central Florida College of Medicine, Orlando, FL, USA

ORCiD

Terri Gotschall, https://orcid.org/0000-0002-6397-1299

Shalu Gillum, https://orcid.org/0000-0002-4285-8924

Nadine Dexter, https://orcid.org/0000-0002-4774-3093

Word Count: 5,179 


\section{INTRODUCTION}

Scholarship encompasses a wide range of activities that includes life-long learning, publishing a variety of article types, presentations, research, and contributing to the field through teaching and mentoring. Health sciences librarians who seek promotion or tenure must navigate the complex landscape of scholarly activities throughout the course of their careers. This practical guide, designed specifically for health sciences librarians, provides a path of scholarly activities, with examples and additional resources to help librarians reach their career goals (See Figure 1). While the guide leads librarians through a scaffolding series of scholarly activities across four levels, where higher levels correspond with career progression and experience, each librarian's experiences navigating through the guide will be different. It is possible steps will be skipped and multiple activities will be in progress on different levels.

\section{A Practical Guide to Scholarly Activity} for Health Sciences Librarians

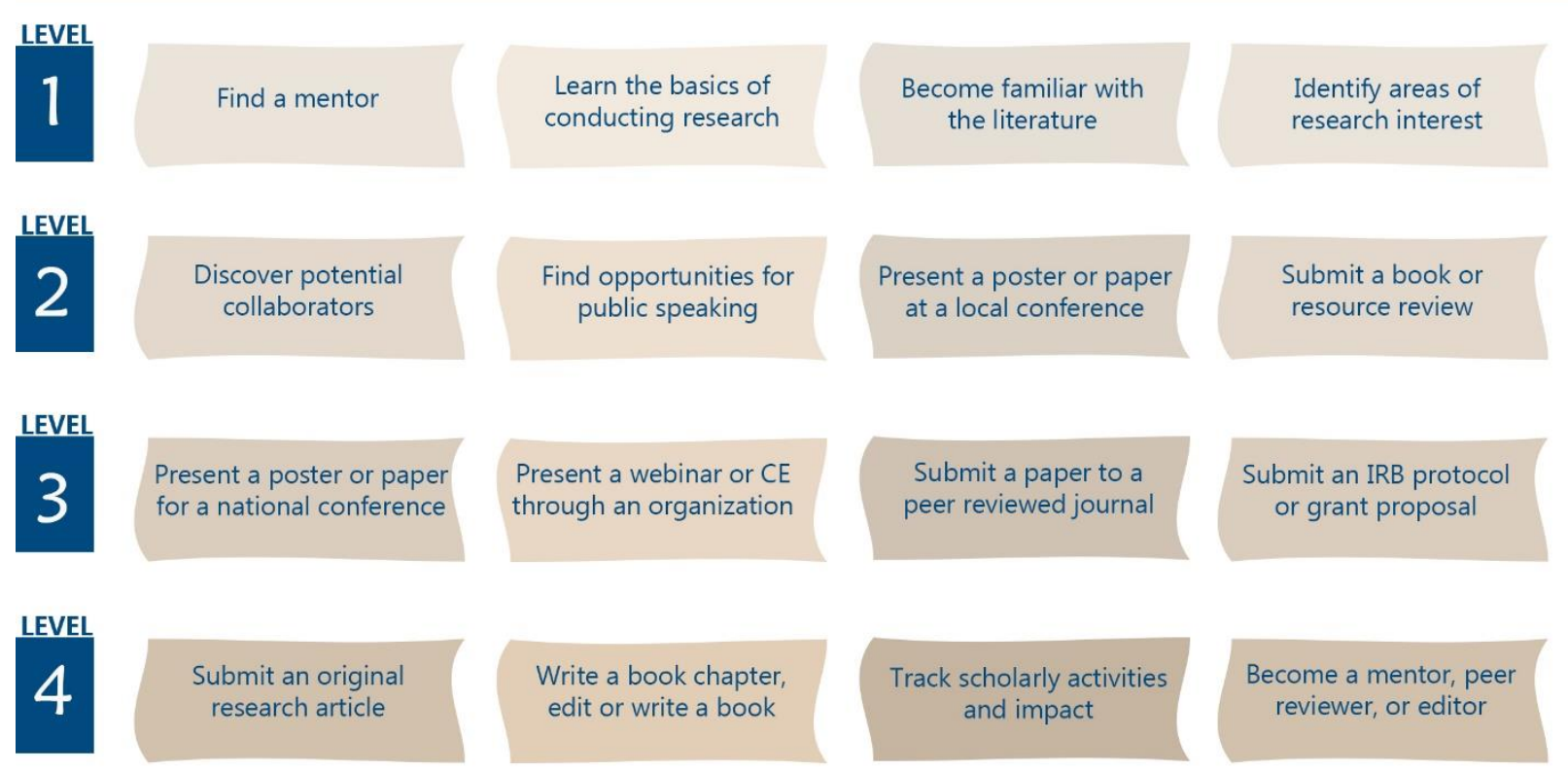


Figure 1. A practical guide to scholarly activity for health sciences librarians.

The guide is modeled on an infographic by Wang et al. for early-career medical educators that provides a three tiered approach, from learning the landscape to publishing an original research article. ${ }^{1}$ The infographic for medical educators includes opportunities specifically for medical doctors, like didactic classroom lectures and grand rounds that librarians may not have access to. This guide, designed specifically for health sciences librarians, includes examples and additional resources to help librarians reach their career goals, and was developed by librarians at various stages along the career path: a new librarian with less than two years of experience, a mid-career librarian with 10 years of experience, and a library director with over 25 years of experience. After a literature review, the authors discovered a gap in the literature providing a practical guide for health sciences librarians' scholarly activities. This guide provides ideas and examples of specific resources to help health sciences librarians on their path to scholarly activity.

Begin with the end in mind; as one embarks on this journey it is beneficial to align one's professional goals to one's institution's mission and goals, as this may lead to more opportunities for a successful career.

\section{LEVEL ONE: EXPLORING THE FIELD}

\section{Find a mentor}

Though especially true for new librarians, all librarians, regardless of where they are in their career, can benefit from mentorship. If possible, new librarians should look for someone at their institution willing to guide them and provide support and time for a truly meaningful experience

for both mentor and mentee. It is important to find someone who has similar experiences in areas 
that match one's professional interests. Mentorship provides mentees access to their mentor's past experiences and network of professional colleagues. For the mentor this activity can engender a "renewal of professional purpose... a sense of satisfaction that one has helped to influence the future of the profession" . ${ }^{2}$ Librarians unable to find a mentor at their institution can tap into several medical library organizations that have mentoring programs. For example, the Medical Library Association's Academy of Health Information Professionals (AHIP) credentialing process matches librarians at the provisional level with an experienced mentor. ${ }^{3}$ The MLA maintains a mentoring/expertise directory. Members can log in and search the directory to connect with a mentor or expert; however, non-members need to contact the association to be connected with a mentor or expert. ${ }^{4}$ In addition, the MLA regional chapter organizations will also partner librarians with a willing mentor if requested.

To have a successful mentorship experience it is important to address the following areas: "structure, objectives, administrative support, and assessment". ${ }^{2}$ It is also important to have clear communication agreements in place. Determining how and when these communications will occur are key to the success of the mentoring relationship. Nothing will destroy a budding mentoring relationship faster then missed phone calls and meetings. It is therefore imperative that both the mentor and the mentee agree on when these connections take place and how they will happen. For example, online video conferencing allows for easy face-to-face meetings, or monthly/weekly phone calls can be scheduled. It is important to stick to the agreed upon meeting times. Build up trust and respect with each other by always communicating as scheduled and with purpose. There are important decisions to be made to begin the mentoring process especially when it revolves around a project. The list below suggests mentee and mentor agreements on the following topics: 
1. Discuss research interests or projects with a mentor.

2. Establish and document future goal(s) for the proposed research with a mentor.

3. Develop and document a research plan.

4. Build a timeline for mentorship milestones and activities during the year.

Once these guard rails are in place, and the means and frequency of the communications are established, then the work can begin, both for the project and for building a new strong mentoring relationship that works well for mentee and mentor.

Librarians new to research could also benefit from finding a research mentor. This may be a different individual than one's professional mentor, and could be another librarian with more research experience, or even a non-librarian researcher. Academic librarians may consider reaching out to a more senior $\mathrm{MD}$ or $\mathrm{PhD}$ faculty member with research experience. Opportunities for research collaboration and possible co-authorship on a publication could result from such partnerships. MLA's Research Caucus Mentoring Program pairs librarians new to research with librarians more experienced in this field. ${ }^{5}$ The American Library Association's Association of College and Research Libraries (ACRL) also offers a "Your Research Coach" program through its College Libraries Section. ${ }^{6}$

\section{Learn the basics of conducting research}

A study published in 2018 showed that only $17 \%$ of librarians believe their Library and Information Studies (MLIS/LIS) degrees adequately prepared them to conduct original research. ${ }^{7}$ The good news is that there are resources to help librarians learn the basics of conducting research. For example, the Institute for Research Design in Librarianship (https://library.lmu.edu/irdl/) prepares participants for careers as librarian-researchers during a 
week-long summer workshop. Participants complete their own research project throughout the following year with support from their mentor and peers. ${ }^{8}$ MLA's Research Training Institute (https://www.mlanet.org/rti) provides an immersive experience that focuses on scholarly research, inquiry, and publishing. With support and resources from the institute, including mentorship, participants complete an original research project of their own design that culminates in a poster presentation at the MLA annual meeting. ${ }^{9}$ MLA's Research Caucus hosts “The Health Sciences Librarian Research Guide" (https://www.mlanet.org/page/test-researchresources), which contains several resources to help librarians with the research process. ${ }^{10}$ Additionally, the National Network of Libraries of Medicine offers convenient online courses and tutorials on conducting research, specializing in data management courses and toolkits. ${ }^{11}$ The American Library Association's Office for Research and Statistics provides the Librarian and Researcher Knowledge Space (LARKS), a website designed for researchers at all levels. For those new to research, the site includes a research methods page, grant resources, guides and book suggestions, and list of conferences to present one's research. ${ }^{12}$ Online classes on research methods, including those found on LinkedIn Learning (formerly Lynda.com), are another way for librarians to learn the basics of conducting research. Finally, there are many books written on the subject, and several written for librarians. Books on research methods in library and information science are a useful guide to refer to while undertaking a research project.

As librarians learn about conducting research, it is important to identify specific areas where support will be needed. For example, statistical analysis support to determine data validity, gaining access to survey tools, data management, or writing support for non-native English speakers. Institutions offer a variety of resources and services through different offices 
and departments; often librarians can take advantage of these resources. This is the right time to explore the resources and services provided by one's institution and create a list of resources and contacts to help support the research process. For more information on Institutional Review Board and grants see the section in level three on writing and submitting an IRB protocol and grant proposal.

\section{Become familiar with the literature}

Before engaging in scholarly activities, it is beneficial to read journal articles in one's area of interest. This increases knowledge, provides background information on the topic, helps to identify key journals and authors to follow, and provides examples of scientific writing styles published in academic journals.

Start by searching PubMed, Scopus, or Web of Science. As key articles are identified, it is useful to collect them using a reference management software such as EndNote, Mendeley or Zotero. These articles may be used in the literature review section of an original research article. Use the "group" feature in the reference management software to organize articles by topic.

After collecting relevant articles, identify key journals and authors to follow. Sorting the records by journal title may unveil journals that publish frequently on the topic. Many databases allow users to save their searches and to create alerts. Setting up a Google Alert, for example, aids the discovery of non-academic writing, including news sites and blogs. Librarians often recommend these features to faculty and students but do not always remember to take advantage of these features themselves.

Another source for finding literature is through social media. ${ }^{13}$ Authors may share links to their works on social media sites, especially if they have published in an open access journal. 
Follow authors with similar research interest on Twitter or LinkedIn to keep up to date with their latest research.

As one becomes familiar with the literature, one is also exposed to the academic style of writing. This provides a foundation for the beginner writer to emulate.

\section{Identify areas of research interest}

While becoming familiar with the literature, a natural curiosity may lead to potential research questions. This is when one begins to formulate an original research question to be explored. Take the time to write down any potential research questions or gaps in the literature that could be expanded into a full research project. Another source of research inspiration is one's own job function in the library. For example, electronic resources or collection development librarians may want to investigate how library resources are being used. Public services librarians, on the other hand, may be interested in information needs of library users, or assessment of library programming and services. Digging deeper into one's own area of librarianship is a great stepping stone to level two, where librarians will find themselves expanding their networks and opportunities for scholarly activity.

\section{LEVEL TWO: FIRST TIME PRESENTATIONS AND PUBLICATIONS}

During level two, as one begins to present and publish, a publisher may request an ORCiD identifier as part of the submission process. An ORCiD account may also be required by an institution for tracking scholarly works. ORCiD is a unique identifier, that is connected to a person. Since it is independent of the person's employer, it moves with that person throughout their career. ORCiD accounts are free, easy to set up, and allow users to collect all of their 
scholarly work in one place. A user can setup their ORCiD account to automatically add scholarship as it is published online, or a user can manually add their scholarship. ${ }^{14}$ This allows users to keep track of many types of scholarship in one place. The unique identifier can be used in databases as a search term, allowing a user to easily access scholarly impact measurements. Finally adding one's ORCiD to an email signature would allow potential collaborators to easily access one's scholarship.

When considering conducting a pilot or preliminary research study that includes human participants see level three's section on writing an IRB protocol.

\section{Discover potential collaborators}

Collaborators provide knowledge and expertise, and share the workload. When possible, start local: teaming up with colleagues with overlapping interests on a scholarly project is a great way to initiate collaborative projects.

Attending an MLA annual meeting or chapter meeting is another way to meet potential collaborators who are interested in similar topics. Take advantage of all the conferences' networking opportunities by participating in social events, dinners, and opening sessions. When attending events make a point to speak with new people. Be approachable, put distracting electronic devices away, look up, smile, and be bold. Paper, poster, and immersion sessions are the ideal time to speak one-on-one with those conducting research in the same area.

Joining one of MLA's caucuses also provides networking opportunities with those of similar interests. Often, conference attendees are looking for companions to have coffee or lunch with, and these informal conversations can lead to project ideas and collaboration opportunities. 
After a caucus meeting is an ideal time to ask someone to continue the conversation over coffee or lunch.

\section{Find opportunities for public speaking at one's library}

In order to build public speaking skills, seek out opportunities to present in front of an audience. This can be in the form of a "lunch and learn", workshop, seminar, lecture, or program held at the library. For librarians whose libraries have regular meetings, these are an easy low-risk setting in which to develop and practice public-speaking skills. Consider creating a few slides on a recently completed project and offering to present it to the library team. This setting could also be used to train other members of the library team on a new policy or procedure in a presentation format.

Teaching information literacy skills, search strategies, reference management or other library tools is another way to practice public speaking. However, if one is new to teaching, observing an experienced librarian providing instruction is a great first step. Co-teaching a session with an experienced librarian allows the experienced librarian to provide feedback to the novice prior to their first solo instruction. The skills and confidence gained from these sessions are useful throughout one's career. These types of activities may be included on a curriculum vitae (CV) and may lead to other speaking opportunities.

\section{Present a poster or paper at a state or regional conference}

State and regional conferences accept papers and posters on a wide variety of topics that are not necessarily based on original research. They often accept posters on innovative programming, lessons learned from the field, case studies, small studies, new technology uses, and more. A 
good place to look for inspiration is one's own annual review and CV; looking back on the accomplishments from the past year may spark an idea worth sharing with other librarians. Presentations at state or regional conferences also provide additional public speaking and networking opportunities. It is advisable to have a mentor or another librarian with scholarly writing experience review any abstracts prior to submission.

At this stage, begin to track scholarly activity. CVs should be updated immediately with publications and presentations. Take a count of how many people attend conference sessions, and keep track of all follow up activities from conferences. The data collected now is beneficial in level four.

\section{Submit a book, product, or media review}

Writing a book, product, or media review is an excellent first publication. Typically, book and resource reviews are not peer reviewed (although they may appear in a peer reviewed journal). However, they do provide a service to the library community, especially librarians who may be reading them for collection or resource development purposes. In addition, they provide experience in following author guidelines and the submission process. In level one, librarians identified their areas of research interest. To get the most out of a book review, select a book in a field of interest. Take notes while reading, to remember key details and to help develop content for the review article. Product and resource reviews provide the opportunity for in-depth learning about a resource.

The Journal of the Medical Library Association accepts book and resource reviews. Some other examples of journals that accept book reviews include:

- Collection Management 
- College \& Research Libraries

- Endnotes: The Journal of the New Members Round Table American Library Association

- Journal of Academic Librarianship

- Journal of Electronic Resources in Medical Libraries

- Journal of Hospital Librarianship

- Journal of Interlibrary Loan, Document Delivery \& Electronic Reserves

- Library Quarterly

- Medical Reference Services Quarterly

- Reference and User Services Quarterly

Examples of journals that accept resource reviews include:

- Collection Management

- Endnotes; The Journal of the New Members Round Table

- Journal of Electronic Resources in Medical Libraries

- Journal of Interlibrary Loan, Document Delivery \& Electronic Reserves

- Public Services Quarterly

- Technical Services Quarterly

Remember to update CV's immediately upon publication.

\section{LEVEL THREE: BUILDING SCHOLARSHIP FOR A NATIONAL AUDIENCE}

\section{Present a poster or paper at a national conference}

Presenting a poster or paper at a national conference is similar to presenting at a state or regional conference; however, due to the increased number of submissions, proposal acceptance rates are typically lower. Some conferences may require proposals to be submitted as structured abstracts. 
For novices looking for guidance on writing a structured abstract, the MLA Research Caucus recommends The Structured Abstract: An Essential Tool for Researchers, https://www.mlanet.org/p/cm/ld/fid=517. ${ }^{15}$ Volunteering to serve as a paper or poster reviewer is a good way to gain insight as to what makes a conference-worthy abstract. A paper or poster previously presented at a state or regional conference could be expanded upon and submitted as an abstract for a national conference, allowing librarians to share their work with a wider audience. This works well with ongoing projects when additional data and analysis has been done, to share as a refreshed poster or paper. Like state and regional conferences, paper and poster presentations offer networking opportunities and a chance to meet future collaborators. Following the trajectory laid out here should provide librarians with ample opportunities to practice their public speaking and presentation skills to a variety of audiences, including larger audiences found at national conferences.

\section{Present a webinar or continuing education course through a state, regional or national organization}

Librarians who have already created and presented a poster, or published a review article, may be ready for the next step in their scholarly journey: giving a webinar or continuing education workshop. Presenting a webinar or continuing education workshop provides librarians with a chance to give back to their profession by creating educational opportunities for other librarians to learn from their experiences and expertise. This may seem daunting, and librarians may doubt whether they have enough content to fill up an entire webinar or workshop. However, with a thoughtfully crafted outline there is always more to discuss than just what made it to the final version of a poster or paper. 
It should be noted that not all librarians at Level 3 will be ready to present a webinar or continuing education workshop. Both scholarly activities require additional work, including creating and submitting a well-written and well-organized proposal and/or application. They may also require some sort of application fee, especially in the case of a continuing education workshop, in order for the author(s) to present the course for credit through a professional organization. Some librarians may find that their institution will provide support for such fees. Webinars and continuing education workshops also require a significant time commitment, not only in creating the proposal and application, presentations and course materials, but also in waiting to find out if one's proposal is accepted and can be presented. If one's proposal is not accepted, ask for feedback to improve a future application. Waiting until reaching Level 4 and having more experience with other scholarly activities is also recommended.

A good first step is contacting a state, regional, or national library organization's continuing education committee to ask if there would be any interest in a particular topic. Unique topics that have not previously been shared in a webinar format will likely have a more positive reception. MLA hosts monthly webinars, which are often one hour to one and a half hours in length. Similarly, some state professional organizations and regional consortia host webinars for their members and are often looking for willing presenters.

Presenting a webinar prior to undertaking a continuing education workshop is recommended. It not only allows librarians to practice delivering their content, but also provides feedback from attendees that can be used to create and refine a longer workshop. Continuing education workshops, typically two to four hours in length, require more planning to create and deliver content within this time frame that is both informational and engaging. Interactive sessions involving attendee participation or small group tasks make for more hands-on and 
meaningful workshops, and also allow for reinforcing of concepts while simultaneously filling out a longer agenda. Webinars and workshops are perfect opportunities to seek collaborations with other librarians, especially those from other institutions. Audience members get the benefit of a variety of voices and experiences, and each individual presenter bears less of the burden of creating and presenting the content.

Workshops and webinars delivered through professional organizations typically ask attendees to provide feedback after the event is over. While sometimes hard to digest, it is important to review feedback in order to refine content and sharpen presenting skills for future presentations.

\section{Submit a paper to a peer reviewed journal}

Journals publish a wide variety of article types other than original research, including literature reviews, columns, commentaries, and letters to the editors. Systematic and literature reviews are typically peer reviewed, whereas columns, commentaries and letter to the editors are usually not peer reviewed. Paper presentations delivered at professional meetings can often be translated into publications submitted for peer review. As a next step on the publishing path, look for article types that are peer reviewed. Gaining experience with the peer review process, especially incorporating constructive feedback into a manuscript, is an important aspect of academic writing. Knowing what to expect from the peer review process will benefit authors in level four when submitting original research manuscripts.

The Journal of the Medical Library Association publishes the peer reviewed columns, Knowledge Synthesis, and Case Reports. The peer reviewed columns, Charting Consumer Health, ReachOut Through Outreach, Specialty of the House, Technology, and Patchwork are 
published in The Journal of Hospital Librarianship. Medical Reference Services Quarterly

editors invite submissions to their peer reviewed columns, Hospital Information Services, Online Updates, Emerging Technologies, and Informatics Education columns. To find a journal in a specific specialty, the EBSCO database, Library Literature \& Information Science Full Text, indexes over 170 full-text journals. ${ }^{16}$ To discover the types of articles a journal publishes, read the author guidelines or "About" page on a journal's website.

\section{Write and submit an IRB protocol or grant proposal}

An institution's Internal Review Board (IRB) approval is required prior to performing original research involving human participants. IRB training is required and typically provided by Collaborative Institutional Training Initiative (CITI) Program. Writing and submitting an IRB protocol requires technical writing skills and special attention to details. Additional training and resources may be available through the institution's IRB office. If completing an IRB protocol seems daunting, librarians take advantage of their institution's resources on submitting IRB protocols, typically found on the Office of Research's website or by contacting the IRB office directly. Research mentors are another great resource for help with writing an IRB protocol. Grant writing also requires technical writing skills. Grants include travel awards for professional development, program awards and research grants. Depending on the research being conducted, it may be necessary to write a grant proposal in order to fund the research. Often institutions provide workshops or courses on how to find and apply for a grant. A good foray into grant writing is to apply for a travel or professional development grant. Take the lessons learned from those grant writing experiences and apply them to writing for an internal grant, those funded by the institution or department. These smaller grants build up the skills needed to apply 
for an external grant. MLA's Research, Development, and Demonstration Project Grant is just one of four research related grants currently offered by MLA. ${ }^{17}$ The National Library of Medicine provides research grants in the area of biomedical informatics and data science. ${ }^{18}$ Though not specifically for health science libraries, the American Library Association offers travel awards, diversity grants, programming event grants, scholarly communication research, academic library impact research grants and more. ${ }^{19}$ Academic institutions often provide resources to help researchers write and submit grant proposals. Additionally, librarians should check their MLA chapters and their regional National Network of Libraries of Medicine websites to see if they provide funding for professional development or research projects.

Whether writing a grant proposal or an IRB protocol, have an experienced mentor or collaborator review the application and provide feedback prior to submission.

\section{LEVEL FOUR: RESEARCH-BASED SCHOLARSHIP AND BECOMING LEADERS IN THE FIELD.}

\section{Original research article}

The ultimate scholarly goal for a health sciences librarian is to publish original research in a peer-reviewed journal, so as to add to the body of knowledge on a particular subject. Original research involves some type of quantitative or qualitative analysis. Not all academic librarians are in a position, or have the skills, to do original research or design and conduct their own research study. There are, however, many opportunities available for librarians to expand their research skills, as described here in level one.

Potential areas of original research for health sciences librarians include public services, information use, technology, or research related to library collections. ${ }^{20}$ A good place to start is 
thinking about services or operations that could potentially be improved in one's own library. Librarians with paper or poster presentations under their belt should consider expanding on those projects, especially if they were submitted under the research category. If conducting a brandnew solo research study sounds daunting, early and mid-career librarians can seek out collaborations with faculty or more experienced librarians, including their research mentor. New librarians collaborating with others need to have a clear understanding of the criteria for being considered an author. The International Committee of Medical Journal Editors (ICMJE)

provides a definition and criteria for one's contributions to be considered authorship. ${ }^{21}$ Establishing the expectations of all collaborators' early in the project and following the ICMJE guidelines will help to ensure all contributors meet the criteria of authorship.

Lastly, researchers may want to consider making their data available by depositing it in an open data repository or institutional repository in accordance with their institution's data policies.

\section{Write a book chapter, edit or write a book}

Another way to participate in level four scholarly activities is by using one's expertise in a subject area to write a book chapter. Expertise gained from completed projects previously shared in a poster or paper can be more fully described in this medium. Books are regularly being written and/or edited by librarians on a variety of subjects. Look for calls for authors or contributors on the listservs of state, regional, and national professional organizations.

Librarians who have put the time and effort into creating and delivering a webinar or workshop may consider taking the next step and transforming their content into their own book. 
Both MLA and the American Library Association provide publishing opportunities for those interested in authoring or editing a book. Writing an entire book, even with another collaborator, can be a challenge due to the amount of content that is required. Seeking other author contributors to write some chapters not only lessens the burden on the primary authors or editors, but also provides scholarly opportunities for other librarians.

Calls for book chapters, entire book authoring, or book editing often require submitting a proposal, and can sometimes be a lengthy multi-step process. Reaching out to either the editor (for book chapters) or committee in charge of reviewing book proposals can be helpful in ascertaining the format and content required. Once accepted to write a chapter or book, review other books by that publisher or books with similar subject matter to get an idea of how they formatted, the writing style and tone, whether images are included, etc., to develop a plan for your own work. There are also books available written for librarians looking to author a book chapter or book, and it may be beneficial to review these prior to writing.

Librarians should be aware that writing or editing a book is often a long-term time commitment that could last up to one year. Most book publishers will require authors and/or editors to submit a timeline for when content will be submitted over the course of the project. However, creating an internal working timeline and calendaring submission dates and other important deadlines will go a long way in keeping such a large project organized and moving forward in a timely manner. Scheduling time to regularly write and edit is equally as important.

A final consideration is administrative support. As authoring or editing an entire book requires considerable time, it is important to be sure that one's supervisor and/or director is supportive of the time that will be devoted to working on such a project. 


\section{Track scholarly activities and impact}

Librarians going up for promotion or tenure, or applying for external grants maybe asked to write a narrative that describes their scholarly impact. Author and article level metrics are frequently used to create scholarly impact narratives. Use scholarly metrics responsibly to track and report scholarly impact for tenure or promotion. For articles, there are three types of metrics: citation, usage, and altmetrics. Citation data refers to how many times an article has been cited. The most common author level metric is a citation-based metric, the h-index. Novices who have only published a few articles may not have an h-index yet, as it takes time for citations to accumulate. Google Scholar profiles and the Scopus and Web of Science databases calculate an author's hindex based on the citations in their databases. Therefore, authors may have a different h-index depending on the database.

Usage data refers to the number of times an article has been viewed or downloaded. Usage data can be found on the publisher's website. Usage counts can also be found in the Web of Science database. Altmetrics include mentions on social media platforms, citations on Wikipedia, discussion on blogs and more. ${ }^{22}$ Altmetrics are used to fill out one's impact story.

Scholarship goes beyond the academic journal: conference presentations, webinars, and continuing education courses also contribute to scholarly impact. Remember to record how many people attend the sessions and keep a record of any follow up discussions. A librarian's scholarly impact narrative could include those details to emphasis the importance of the presentation. For example, a librarian gave a presentation at a national conference to an audience of 60 people. After the conference, the librarian received three inquiries from other institutions and an invitation to be interviewed for a blog post. 
Whenever possible try to tie scholarly activities to the mission, values, or goals of the institution or library. Consider how the scholarship fits into the larger scope and clearly write out the connections. For example, to demonstrate outreach, include the number and location of external collaborations in the scholarly impact narrative. It is best not to rely on one metric, but to use a combination of metrics to help create a complete scholarly impact narrative. For more information on types of metrics visit the metric toolkit website (https://www.metricstoolkit.org/), which provides an overview of author, article, and journal level metrics, including the strengths and weakness, and appropriate use of each metric. ${ }^{23}$

\section{Become a mentor, peer reviewer, or editor}

It is important to find ways to make contributions to the health sciences librarian profession. Librarians at level four are encouraged to look for opportunities to become a mentor, a peer reviewer or an editor. Mentorship plays a critical role in setting a standard and model for those individuals who want to be involved in research and ultimately for the preparation of the next generation of health sciences librarians. ${ }^{24}$ Mentoring is a great responsibility and can provide profound influence to the mentee, both personally and professionally.

Several professional library organizations offer mentorship opportunities, including at the regional and national levels. MLA invites librarians to sign up to be a mentor to new or midcareer librarians and those seeking AHIP membership. Librarians who have undertaken any type of leadership training programs might consider reaching out to those programs to see if mentorship opportunities exist within those programs. Informal mentoring relationships can also be developed within one's own library. Consider mentoring a newer librarian—one possibly still at level one, for example — or fostering a peer mentoring relationship with a colleague. This type 
of informal mentoring relationships can even exist across institutions. Connections made throughout one's career, from attending professional meetings to collaborating on a presentation or other scholarly activity, open the door for future mentoring relationships.

Another common level four activity is serving as a peer reviewer. Peer reviewers not only get the opportunity to see articles and chapters long before they are published, but they also provide the professional expertise needed to add to the body of peer reviewed literature. Calls for peer reviewers for individual journals often come across listservs of professional organizations; however, interested librarians can also contact the editorial board of a specific journal to inquire if they are seeking peer reviewers. The experience can teach even experienced librarians a lot about the life cycle of peer reviewed literature, along with providing an opportunity to give back to the profession.

Librarians at level four should also seek out opportunities to serve as an editor. Editorship opportunities can be found at the state, regional, or national level. A good prerequisite to becoming a column or journal editor is serving as editor of a newsletter or blog for a state or regional organization, such as an MLA chapter. After gaining confidence as an editor for a newsletter or blog, librarians can seek opportunities to serve as an editor for scholarly journals or books. This experience can help librarians to grow professionally and can sharpen writing skills.

Mentoring, peer reviewing, and editing provide great opportunities to support the medical library profession. Guiding new librarians in a meaningful and thoughtful manner for professional development and personal growth are also important ways to show support for the medical library profession.

\section{Final Thought}


Health sciences librarians are not always given a clear roadmap to chart out their careers. New librarians may find it helpful to think of their careers in terms of levels of scholarly activities, moving from novice to expert. This creates more attainable goals and a clearer path of activities to accomplish at various stages in one's career.

\section{Acknowledgement}

Thank you to Carly Lambert for providing research support and to Natasha Williams for reviewing the manuscript.

\section{REFERENCES}

1. Wang, Flint, Corrie Stankiewicz, Nadia Bennett, and Jennifer Myers. "Hit the Ground Running: Engaging Early-Career Medical Educators in Scholarly Activity." [In eng]. Acad Med (Apr 16 2019). https://doi.org/10.1097/acm.0000000000002761.

2. $\quad$ Lee, Marta. "Growing Librarians: Mentorship in an Academic Library." Libr Lead Manag 23, no. 1 (2009): 31-37.

3. "Academy of Health Information Professionals." accessed October 31, 2019, https://www.mlanet.org/p/cm/ld/fid=41.

4. $\quad$ "Professional Development: Find a Mentor." accessed April 22, 2020, https://www.mlanet.org/p/cm/ld/fid=45.

5. "Research Mentoring Program." accessed October 31, 2019, https://www.mlanet.org/p/cm/ld/fid=955. 
6. "Your Research Coach" Program." accessed November 1, 2019, http://www.ala.org/acrl/aboutacrl/directoryofleadership/sections/cls/clswebsite/collprogdi sc/researchcoach.

7. Kennedy, Marie, and Kristine Brancolini. "Academic Librarian Research: An Update to a Survey of Attitudes, Involvement, and Perceived Capabilities." [In English]. Article. Coll Res Libr 79, no. 6 (Sep 2018): 822-51. https://doi.org/10.5860/crl.79.6.822.

8. "Institute for Research Design in Librarianship." accessed January 14, 2020, https://library.lmu.edu/irdl/.

9. "MLA Research Training Institute for Health Sciences Librarians." accessed October 31, 2019, https://www.mlanet.org/rti.

10. "The Health Sciences Librarian Research Guide." accessed November 1, 2019, https://www.mlanet.org/page/test-research-resources.

11. "Courses and Workshops." accessed October 25, 2019, https://nnlm.gov/data/coursesand-workshops.

12. "Librarian and Researcher Knowledge Space." accessed October 25, 2019, http://www.ala.org/tools/research/larks.

13. Akers, Katherine. "Report from the Medical Library Association's Insight Initiative Summit 2: Meeting the Evolving Information Needs of Library Stakeholders." [In eng]. Journal of the Medical Library Association 107, no. 2 (2019): 137-50. https://doi.org/10.5195/jmla.2019.669.

14. "Orcid: Connecting Research and Researchers." accessed January 29, 2020, https://orcid.org/about. 
15. "The Structured Abstract: An Essential Tool for Researchers ", accessed January 21, 2020, https://www.mlanet.org/p/cm/ld/fid=517.

16. "Library Literature \& Information Science Full Text." accessed August 15, 2019, https://www.ebsco.com/products/research-databases/library-literature-informationscience-full-text.

17. "Grants, Scholarships, and Fellowships." accessed November 1, 2019, https://www.mlanet.org/p/cm/ld/fid=47.

18. "Grants and Funding: Extramural Programs (Ep)." accessed November 1, 2019, https://www.nlm.nih.gov/ep/Grants.html.

19. "ALA Grants." accessed November 1, 2019, http://www.ala.org/awardsgrants/awards/browse/grnt?showfilter=no.

20. Lessick, Susan, Carol Perryman, Brooke Billman, Kristine Alpi, Sandra De Groote, and Ted Babin, Jr. "Research Engagement of Health Sciences Librarians: A Survey of Research-Related Activities and Attitudes." [In eng]. J Med Libr Assoc 104, no. 2 (Apr 2016): 166-73. https://doi.org/10.3163/1536-5050.104.2.015.

21. "Defining the Role of Authors and Contributors." Accessed April 23, 2020, http://www.icmje.org/recommendations/browse/roles-and-responsibilities/defining-therole-of-authors-and-contributors.html

22. "An Introduction." accessed November 1, 2019, https://www.altmetric.com/aboutaltmetrics/what-are-altmetrics/.

23. "Metrics Toolkit: Helping You Navigate the Research Metrics Landscape." 2020, accessed January 14, 2020, https://www.metrics-toolkit.org/. 
24. Fuller, Sherrilynne. "Enabling, Empowering, Inspiring: Research and Mentorship through the Years." [In eng]. Bull Med Libr Assoc 88, no. 1 (Jan 2000): 1-10. https://www.ncbi.nlm.nih.gov/pmc/articles/PMC35192/pdf/i0025-7338-088-01-0001.pdf. 